\title{
STUDIES IN TRAUMATIC EPILEPSY \\ I. FACTORS INFLUENCING THE INCIDENCE OF EPILEPSY AFTER BRAIN WOUNDS
}

BY

\author{
W. RITCHIE RUSSELL and C. W. M. WHITTY
}

From the Department of Neurology, Radcliffe Infirmary, Oxford

There is no doubt that epilepsy presents a valuable means of studying cerebral function. Apart from the problem of what factors cause the abnormal neuronal discharge which constitutes the fit, the pattern of attack can give information about the function of the area concerned when the site of injury is known. For this purpose the study of cases of post-traumatic epilepsy following the small penetrating brain wounds of modern warfare is of special value. In this type of injury high velocity metal fragments often cut into the brain without disturbing consciousness, or " explode" a group of bone fragments for a distance of a few centimetres into the brain, while the metal fragment glances away. In either case a highly localized lesion often results, and thanks to the advances of surgery and of the use of antibiotic drugs, most of these wounds were quickly rendered sterile and healed by first intention after débridement. The evidence for localization in these small wounds is often precise, and this can be correlated with the content and sequence of events in an epileptic fit. When the wound produces a recognizable neurological deficit, the behaviour of this during the attack can also provide information. For all these reasons traumatic epilepsy has been a constant source of interest, and after the first world war gave rise to many special studies both as regards the incidence of post-traumatic epilepsy and the clinical features of the fits.

The study presented here is concerned with a follow-up of 820 surviving cases of penetrating brain wound suffered during the second world war by British service personnel. During the second war a special effort was made to collect accurate information of cases of brain wounds. The records of this group of cases are carefully preserved and a follow-up system has been kept in operation ever since, by means of a Head Injury Advice Bureau. The records must to some extent depend on postal enquiry, which includes a detailed questionnaire about the fits completed by witnesses, but doubtful cases are re-admitted for further study, and Ministry of Penisons documents are available for consultation. The evidence available as to the nature of faints or fits has been sifted by the writers themselves, and a decision as to the nature of " attacks" has been made on their clinical features, as this is still by far the most reliable method of diagnosis. Electroencephalographic evidence was excluded from the assessment.

\section{Incidence of Post-traumatic Epilepsy}

So far as incidence is concerned, recorded figures differ widely. This is due in part to the type of attack accepted as "epileptic", but partly to variations in the type of injury studied, and also to the differing duration of follow-up after injury. In wounds with definite dural penetration and actual brain damage Wagstaffe (1928) found $27 \%$ epileptics, while Gliddon (1943) in a detailed follow-up of 500 cases gave a figure of $66.7 \%$ for cases with brain penetration and retained bone fragments. Both these figures are from the 1914 war cases and differences in the length of follow-up account in part for the wide disparity. Other late reviews support a high figure. Thus Ascroft (1941) found a $45 \%$ incidence of epilepsy from the records of Ministry of Pensions cases of head wounds with dural penetration. Baumm (1930) gave $44 \%$ in a series of 562 cases, while Credner (1930) in one of the largest reported series, quotes the incidence as $49.5 \%$ of 1,234 cases. The bare presentation of figures is however to some extent misleading. For example, the patient who has one convulsion in five years and the patient who has a fit every three weeks, though both are suffering from traumatic epilepsy, show very different degrees of cerebral dysrhythmia and disability.

It should be clearly understood that in the present analysis the occurrence of a single epileptic fit or focal attack involves the case being classified as epileptic. On the other hand a few cases which have attacks, the nature of which is uncertain owing 
to lack of detail, are classified in this study as not having epileptic fits.

Fits which appeared in the early days after wounding are also included, but as one of us has previously (Whitty, 1947) reported, most of these have late epilepsy also. The small number which have fits only in the acute stage are noted separately in some of the tables.

Table I shows that the incidence of epilepsy in this series of 820 cases is already $43 \%$ five years after wounding. The length of follow-up in all

TABLE I

INCIDENCE OF EPILEPSY FIVE YEARS AFTER PENETRATING BRAIN WOUNDS

\begin{tabular}{|c|c|c|c|c|}
\hline $\begin{array}{l}\text { Cases with fits .. } \\
\text { Cases with no fits : } \\
\text { Duration of follov } \\
\text { over } 5 \text { years } \\
2-5 \text { years } . \\
1-2 \text { years } \ldots \\
\text { at }<1 \text { year }\end{array}$ & $\begin{array}{l}\cdots \\
\text {-up : } \\
\cdots \\
\cdots \\
\cdots\end{array}$ & $\begin{array}{l}\cdots \\
\\
\cdots \\
\because \\
\cdots\end{array}$ & $\left.\begin{array}{r}\cdots \\
403 \\
21 \\
21 \\
19\end{array}\right)$ & $\begin{array}{l}356(43 \%) \\
464(57 \%)\end{array}$ \\
\hline Total & $\ldots$ &.. & $\ldots$ & 820 cases \\
\hline
\end{tabular}

non-epileptics is also given, and some of the 61 cases not yet followed-up for five years must certainly have developed epilepsy before that period and so have increased the true incidence of this complication.

So far as disability is concerned, the frequency of fits and their type during the five-year period is shown in Table II for 279 cases where this information was available. It is clear that in over half the cases fits have been very infrequent and are unlikely to be a serious disability.

TABLE II

FIVE-YEAR FOLLOW-UP OF FREQUENCY OF EPILEPTIC FITS

\begin{tabular}{c|c|c|c|c}
\hline $\begin{array}{c}\text { No. of Fits in } \\
5 \text { years }\end{array}$ & Focal & Generalized & Both & Totals \\
\hline \begin{tabular}{c|c} 
Less than 5 in all \\
1 or 2 a year $\cdots$
\end{tabular} & 15 & 75 & 40 & 130 \\
Over 2 a year* $\cdots$ & 21 & 23 & 20 & 55 \\
\hline Totals $\ldots$ & 48 & 142 & 89 & 94 \\
\hline
\end{tabular}

* In the over-two-a-year group, 20 had had no fits for the last three years of the follow-up period.

\section{Comparison with First World War Cases}

It was naturally hoped that the great improvements in surgical treatment in the second world war would reduce the incidence of post-traumatic epilepsy. This hope was based on the generally accepted view (Penfield, 1927) that progressive gliosis is an important factor in the development of an epileptogenic focus, and that as wound infection was abolished and efficient primary débridement instituted, so there would be less scarring and the incidence of epilepsy would consequently fall. There is no doubt that the contrast as regards wound infection and thorough débridement in the two wars is most striking. In Ascroft's (1941) series only a quarter of the wounds were healed within 15 days, whereas in the second war less than $15 \%$ failed to heal by first intention (Cairns, 1948). In spite of this remarkable change, however, the incidence of traumatic epilepsy does not seem to be significantly reduced.

Not only does the figure presented in this series certainly err on the low side, but a considerable number of patients may be expected to develop their first fit at a longer interval after injury than the five-year period used. Baumm (1930), for example, found that $15 \%$ of his cases had the first fit more than five years after injury, while in Ascroft's (1941) series this figure was $10 \%$. It is clear, therefore, that the present series in a 10-year follow-up is likely to give figures for post-traumatic epilepsy which will be about $50 \%$, and just as high as those reported from the first war.

\section{Time of Onset of Post-traumatic Epilepsy}

The interval after wounding at which the first fit occurred is known accurately in 277 cases. These intervals are indicated in Table III, and they are compared with the figures published by Ascroft and Baumm. There is no obvious explanation for the wide variations in the interval between the injury and the first fit. The effects of progressive scarring here also fail to provide a convincing explanation. The difference may depend partly on the site of wound, and the time of onset in wounds of various areas is shown in Table IV. These figures indicate that for frontal wounds the first fit tends to occur later than for wounds in other regions of the brain. It will also, however, be shown later that frontal wounds tend to cause general convulsions without a remembered aura.

TABLE III

TIME OF ONSET OF EPILEPSY AFTER WOUNDING *

\begin{tabular}{|c|c|c|c|c|c|c|}
\hline \multicolumn{2}{|l|}{ Time of Onset } & \multicolumn{2}{|c|}{ This Series } & \multicolumn{2}{|c|}{ Ascroft } & \multirow[t]{2}{*}{ Baumm } \\
\hline Under 1 month & $\cdots$ & \multirow{3}{*}{\multicolumn{2}{|c|}{$\begin{array}{l}\left.\begin{array}{l}36 \\
84 \\
61\end{array}\right\} 181 \\
(73 \%)\end{array}$}} & \multirow{3}{*}{$\left.\begin{array}{l}19 \\
22 \\
15\end{array}\right)$} & \multirow{3}{*}{$\left(\begin{array}{c}56 \\
(75 \%)\end{array}\right.$} & \\
\hline $1-6$ months & $\cdots$ & & & & & \multirow[t]{2}{*}{$122(60 \%)$} \\
\hline 6-12 ", & .. & & & & & \\
\hline $1-2$ years.. & . & 46 & $(18 \%)$ & 10 & $(13 \%)$ & $42(20 \%)$ \\
\hline $\begin{array}{lll}2-5 \quad, \quad \ldots \\
\end{array}$ & . & 21 & $(9 \%)$ & 9 & $(12 \%)$ & $39(20 \%)$ \\
\hline Total & $\cdot$ & 248 & & 75 & & 203 \\
\hline Over 5 years & .. & 9 & & 9 & & 37 \\
\hline
\end{tabular}

* Cases with fits only within a month of wounding are excluded (there were 20). Figures for the over-five-year interval are excluded from the percentage analysis as our records are incomplete fluded this interval. 
TABLE IV

COMPARISON OF INTERVALS AFTER INJURY AND FIRST FIT WITH APPROXIMATE SITE OF INJURY

\begin{tabular}{|c|c|c|c|c|c|c|c|}
\hline \multicolumn{3}{|c|}{ Onset } & Frontal & Central & Temporal & Occipital & \multirow{2}{*}{$\frac{\text { Totals }}{20^{*}}$} \\
\hline Under 1 month & only & $\cdots$ & 5 & 11 & 0 & 4 & \\
\hline $\begin{array}{l}\text { Under } 1 \text { month } \\
1-6 \text { months }\end{array}$ & $\cdots$ & $\ddot{x}$ & $\left.\begin{array}{rl}8 & 11 \% \\
18 & 24 \%\end{array}\right\} 35 \%$ & $\left.\begin{array}{ll}17 & 14 \% \\
48 & 39 \%\end{array}\right\} 53 \%$ & $\left.\begin{array}{l}526 \% \\
6 \\
31 \%\end{array}\right\} 57 \%$ & $\left.\begin{array}{r}618 \% \\
1236 \%\end{array}\right\} 54 \%$ & $\begin{array}{l}36 \\
84\end{array}$ \\
\hline \multirow[t]{2}{*}{$\begin{array}{l}6-12 \\
1-2 \text { years } \\
2-5,,\end{array}$} & $\begin{array}{l}\cdots \\
\cdots \\
\cdots\end{array}$ & $\begin{array}{l}\cdots \\
\cdots\end{array}$ & $\left.\begin{array}{ll}18 & 24 \% \\
20 & 27 \% \\
10 & 14 \%\end{array}\right\} 65 \%$ & $\left.\begin{array}{rr}35 & 29 \% \\
16 & 13 \% \\
6 & 5 \%\end{array}\right\} 47 \%$ & $\left.\begin{array}{rr}3 & 16 \% \\
4 & 21 \% \\
1 & 5 \%\end{array}\right\} 42 \%$ & $\left.\begin{array}{ll}5 & 15 \% \\
6 & 18 \% \\
4 & 12 \%\end{array}\right\} 45 \%$ & $\begin{array}{l}61 \\
46 \\
21\end{array}$ \\
\hline & & & 74 & 122 & 19 & 33 & 248 \\
\hline $\begin{array}{l}\text { Over } 5 \text { years } \\
\text { Not known }\end{array}$ & 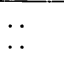 & $\cdots$ & $\begin{array}{r}4 \\
27\end{array}$ & $\begin{array}{r}3 \\
29\end{array}$ & $\begin{array}{l}2 \\
5\end{array}$ & $\begin{array}{r}0 \\
11\end{array}$ & $\begin{array}{r}9^{*} \\
72^{*}\end{array}$ \\
\hline
\end{tabular}

* Excluded from the percentage analysis.

These therefore tend not to have recognizable focal characters, and as Baumm (1930) observed, fits with focal features are more likely to develop soon after wounding. These figures are plotted as curves in Fig. 1, and show that there is a difference in behaviour between frontal wounds and wounds of other regions.

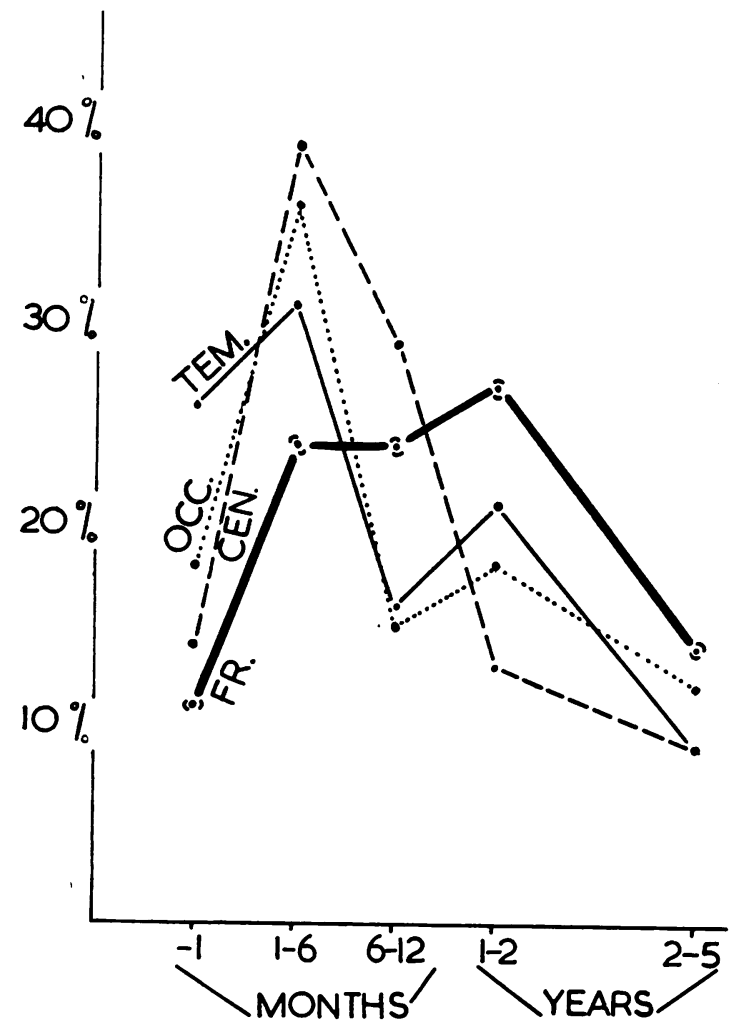

Fig. 1.-The percentage figures from Table IV are charted and illustrate the tendency for epilepsy after frontal wounds (FR.) to develop later than after Central (CEN.), temporal (TEM), or occipital (OCC.) wounds.

\section{Possible Causes of Traumatic Epilepsy}

In any given case there are probably several factors contributing to the production of epilepsy. These may be conveniently considered under anatomical and physiological headings. The segregation is artificial but useful. In the first group are site and extent of injury and the secondary effect of sepsis on these ; in the second are the abnormal functioning of groups of neurons in or immediately around a damaged area, irritative lesions, or the functional changes in neurons at a distance from the lesion as a result of the removal of the influence of the destroyed area, release phenomena, or the effects of sepsis on these two mechanisms, and perhaps constitutional predisposition, though this may conceivably also depend on anatomical factors.

Of these factors, sepsis and incomplete débridement of dead brain tissue as causes of subsequent progressive scarring have often been considered important. However, as Penfield (1927) points out, where injured cerebral tissue is cleanly removed, such cicatricial contraction is largely eliminated. Our figures, from this series of cases where the incidence of sepsis and incomplete débridement have certainly been much lower than formerly, do not support such a view. That acute sepsis of brain or meninges may sometimes precipitate a fit or series of fits must be accepted. One of us (Whitty, 1947) has reported cases in which the occurrence of fits in the acute stage provided the earliest sign of the development of wound infection. In the same way recurrent sepsis in these cases may give rise to recurrent fits. However, the role of early sepsis in the development of later epilepsy seems to be much more uncertain. Superficial wound sepsis has very different and less widespread pathological sequels than those of deep brain infection with prolonged hernia or fungus formation. But even the latter seems relatively unimportant in causing late fits ; for in this series only $54 \%$ of 112 cases with early fungus, abscess or meningitis 
developed persistent epilepsy, a figure little greater than that provided by the whole series.

Previous writers have pointed out that the site of the brain wound affects the incidence of fits. Ascroft (1941) considered that fits frequently followed wounds around the Rolandic area and diminished in incidence as the poles of the brain are approached, though he utters a caveat about the accuracy of localization in his material. Baumm's figures also support this : $67.7 \%$ of fits in the " central parietal region" compared with $15.8 \%$ in the frontal and $6.9 \%$ in the occipital areas, though Credner (1930) finds a smaller difference with $47 \cdot 3 \%$ parietal and $45 \%$ frontal. In Fig. 2 and Table V, the findings in our material are shown. The figures certainly support a higher incidence in the central region.

In Fig. 2 the site of wounding is charted for over 600 cases which have either developed epilepsy
TABLE V

COMPARISON OF SITE OF WOUND WITH INCHDENCE OF FITS CALCULATED FROM FIG. 2*

\begin{tabular}{c|c|c|c}
\hline $\begin{array}{c}\text { Reference } \\
\text { to Fig. 2 }\end{array}$ & Site of Wound & Totals & $\begin{array}{c}\text { Cases with } \\
\text { Fits }\end{array}$ \\
\hline A & Prefrontal and inferior frontal & 160 & $63(39 \%)$ \\
\hline B & Motor and premotor & 127 & $70(55 \%)$ \\
\hline C & Parietal lobe & 170 & $111(65 \%)$ \\
\hline D & Temporal lobe & 71 & $27(38 \%)$ \\
\hline E & Occipital lobe & 73 & $28(38 \%)$ \\
\hline & Total & 601 & $299(48 \%)$ \\
\hline
\end{tabular}

* The $O s$ and $X s$ are collected from the five regions marked on Fig. 2 as A, B, C, D, E. The higher figure for traumatic epilepsy compared to Table $I$ is explained in the text.

(X) or have not developed epilepsy at a five-year follow-up (O). Cases which have not reported fits and have been followed up for less than five years are therefore excluded, whereas those reporting fits during a short follow-up period are included. This weights the selection of cases for charting slightly in favour of those developing epilepsy, and for this reason the charted cases show an incidence of epilepsy of $48 \%$ as compared to $43 \%$ in the analysis in Table $I$. Table $\mathrm{V}$ is prepared from Fig. 2 by comparing the number of Os and $\mathrm{Xs}$ in five regions, the dividing lines being as shown in Fig. 2. Thus the percentages shown in Table $\mathrm{V}$ also show the bias (about 5\%) towards
Fig. 2 ( $a$ and $b$ ).-Charts to show the site of wounding in over 600 cases of penetrating brain wound. Charting depends on measurements taken from skull radiographs (Russell, 1947). Wounds which lie within $5 \mathrm{~cm}$. of the sagittal line are placed in the halo outside of the skull outline. The cases marked $\mathbf{X}$ developed posttraumatic epilepsy while those marked O showed no epilepsy at a five-year follow-up. The lines divide the cases into five groups which are compared in Table $\mathrm{V}(\mathrm{A}, \mathrm{B}, \mathrm{C}, \mathrm{D}$, and $\mathrm{E})$.

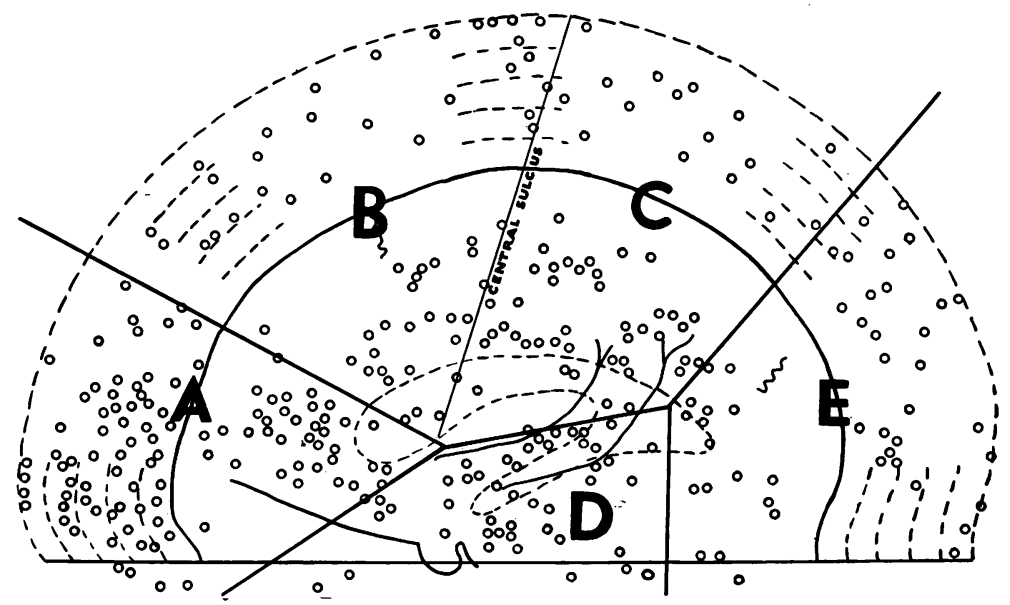


raising the proportion developing epilepsy. The relative incidence of epilepsy in the five regions is, however, clearly shown.

So far as exact extent of wound is concerned, reliable estimates are difficult to obtain, but taking 103 cases with persistent hemiplegia as representing more extensive injuries, the percentage of those with fits is 66. When persistent monoplegia is considered (47 cases), the figure is $47 \%$. It seems therefore that patients with more extensive wounds are only slightly more prone to develop fits, though it must be remembered that a persistent hemiplegia represents not only a more extensive wound, but also a specific anatomical site of wounding, and that this latter factor may be the causal one. If we compare persistent left and right hemiplegias, the percentage of epileptics is little different, being $62 \%$ in the right and $72 \%$ in the cases of left-sided hemiplegia.

The influence of a constitutional factor has not been considered here, because facilities for obtaining information about epilepsy in the family tree, even when limited to siblings and parents, were not thought to be reliable. Logically this factor may be expected to play some part in incidence, or at least in the frequency with which fits occur.

\section{Mechanisms of Fit Production}

All the foregoing factors must finally exert their influence on cerebral physiology in such a way as to produce a fit. The remarkable way in which epileptic phenomena may be reproduced by electric stimulation of the brain (Penfield and Rasmussen, 1950) draws attention to the possibility of traumatic epilepsy being due to a positive irritative phenomenon. It should be pointed out, however, that the spontaneously occurring fit is just as likely to be a release phenomenon.

The occurrence of inhibitory fits, either focal or general, requires to be fitted in with any theoretical conception. These will be studied in their varying forms in a later section. One of us (Russell, 1951) in a preliminary reference to some of these figures has drawn attention to the tendency for a one-toone ratio to develop between the total numbers of cases of brain wound which do and do not develop fits. Further, Penfield (1952) refers to the cure-rate of traumatic epilepsy by operative excision of a brain scar or focus as about the same $(50 \%)$. The same figure has been reported by Jooma, Pennybacker, and Tutton (1951) for the incidence of epilepsy after brain abscess. This one-to-one ratio suggests a balance of two equally important factors which may swing towards or against epilepsy developing, according to which of the two factors is most damaged.
There is physiological evidence that neurons have spontaneous discharges which are normally modified, enhanced or decreased by impulses reaching them via the boutons of other neurons (Brazier, 1951). In a group of neurons relatively isolated by trauma to surrounding cells or fibres spontaneous discharges may occur which are largely freed from the normal influence of other cells. If the influence removed is mainly excitatory, reduced discharge will result. This might show itself either as a permanent loss of function of these neurons, or, if the excitation removed was smaller, as an episodic loss of function when for any reason the remaining excitatory impulses reaching the neurons fall below a critical level. Per contra, if the removal is mainly inhibitory, an abnormally great discharge will ensue. The nature of the clinical correlate of this discharge, the epileptic fit, will presumably depend on the function of the cells firing. If in the area of the motor cortex, a focal motor attack would result. If the remaining cells were themselves normally of mainly inhibitory function, then the clinical result would be a focal inhibitory attack. The basic physiological lesion in any case would be an upset in the normal balance of influences playing on the various neurons. Such a formulation as the above would account for a focal attack or the "local sign" of a more generalized one. The pathways available to the initial abnormal discharge (availability would be determined both by anatomical considerations, such as the site of the original discharge, the presence of damaged and undamaged fibres, etc., and by physiological considerations such as whether synapses are refractory or excitable) would determine whether and how far the discharge spread, that is, whether the fit became generalized. On such an explanation it would be expected that there would be areas from which generalized fits would be readily excited, and others where focal attacks would be more common; but also that generalized attacks could sometimes be evoked from any area. The fixed anatomical connexions of a region would determine its general tendency for predominantly focal or general response, but the physiological " set" of excitation and inhibition in surrounding neurons at a given moment would determine whether a discharge remained localized or not. This is in fact very much the picture seen in traumatic epilepsy.

So far as the general distribution of wounds is concerned, in this series one of us (Russell, 1947) has previously suggested that injury to inhibitory (suppressor) areas might be especially epileptogenic, since this might result in a removal of some degree of normal inhibition from all areas with neuronal 
connexions from the damaged area. However, the evidence is not convincing. Moreover, the argument might be applied, mutatis mutandis, to the production of akinetic or inhibitory attacks from damage to areas mainly excitatory. As may be seen from Fig. 2, there are areas of wounding where the incidence of epilepsy is high and others where it appears low, but statistical analysis reveals only a random distribution of positive and negative wounds. One point does however clearly emerge from this analysis, though its meaning is not very apparent. Wounds lying within $5 \mathrm{~cm}$. of the sagittal line are charted in the halo of the skull outline, and they are found to have a much lower incidence of epilepsy than the wounds charted within the main outline. The figures are given in Table VI. The difference is highly significant $(P<\cdot 001)$. It is possible that this also may reflect an anatomical factor, and the question will be considered further in a later section.

TABLE VI

INCIDENCE OF EPILEPSY IN WOUNDS OF MEDIAL AND LATERAL PARTS OF HEMISPHERES *

\begin{tabular}{l|c|c}
\hline & Within Skull Outline & \multicolumn{1}{|c}{ In Halo } \\
\hline Total & $\begin{aligned} 252 \\
\text { Wounds with fits } . .\end{aligned}$ & $92 \quad(35 \%)$ \\
\hline
\end{tabular}

* Table prepared from Fig. 2.

By way of contributing to the anatomy and physiology of various brain regions, the sections which follow are devoted to analysis of the various types of epileptic phenomena which were observed to occur spontaneously in this series of cases. It is hoped that these studies of spontaneously occurring fits will make some addition to the knowledge gained by other workers (Foerster and Penfield, 1930 ; Penfield and Erickson, 1941) whose attention has been perhaps specially devoted to the effects of electrical stimulation of the brain at operation in these cases.

\section{Summary}

A five-year follow-up of 820 cases of brain wounds from the 1939-45 war. is reviewed from the standpoint of traumatic epilepsy, and as an introduction to more detailed studies of groups of cases which will follow.

Overall incidence of epilepsy and the time of onset of first fit after wounding where known, are given for this series. Incidence is already over $43 \%$ five years after wounding. This figure, despite great improvements in surgical technique and the avoidance of sepsis, is about the same as was reported from the 1914-18 war cases, and it is therefore suggested that progressive gliosis and scarring per se cannot provide an adequate explanation for the occurrence of traumatic epilepsy.

Figures showing the wide variations in the individual case of the frequency of fits are given.

The incidence of epilepsy in wounds of different areas of the brain and of varying severity are compared.

The possible " causes" of traumatic epilepsy are discussed in relation to anatomical and physiological mechanisms.

Acknowledgments will be made in a later section of this study.

\section{REFERENCES}

Ascroft, P. B. (1941). Brit. med. J., 1, 739.

Baumm, H. (1930). Z. ges. Neurol. Psychiat., 127, 279. Brazier, M. A. B. (1951). The Electrical Activity of the Nervous System. London.

Cairns, H. (1948). N.Z. med. J., 47, 95.

Credner, L. (1930). Z. ges. Neurol. Psychiat., 126, 721. Foerster, O., and Penfield, W. (1930). Brain, 53, 99.

Gliddon, W. O. (1943). Canad. med. Ass. J., 49, 373.

Jooma, O. V., Pennybacker, J. B., and Tutton, G. K. (1951). Journal of Neurology, Neurosurgery and Psychiatry, 14, 308.

Penfield, W. (1927). Brain, 50, 499.

, and Erickson, T. C. (1941). "Epilepsy and Cerebral Localization." Springfield, Ill. , and Rasmussen, T. (1950). "The Cerebral Cortex of Man." New York.

(1952). Journal of Neurology, Neurosurgery and Psychiatry, 15, 73.

Russell, W. R. (1947). Brain, 70, 225.

- (1951). Journal of Neurology, Neurosurgery and Psychiatry, 14, 35.

Wagstaffe, W. W. (1928). Lancet, 2, 861.

Whitty, C. W. M. (1947). Brain, 70, 416. 